\title{
Modern information and educational environment: new possibilities of designing and implementing measures to counter extremist sentiments among the students
}

\author{
Julia Gorbunova ${ }^{1, *}$ \\ ${ }^{1}$ Moscow Technological Institute, 199334, Moscow, Russia
}

\begin{abstract}
The article is devoted to the problem of counteraction of the ideology of terrorism and extremism in the youth environment. The role of Russian educational institutions (including universities) in organizing this opposition is shown. The new opportunities that modern information and education space creates for educational and preventive work among the students are discussed. The necessity not only to develop and creatively use these opportunities within individual educational institutions are affirmed, but also to share positive experiences as widely as possible promoting successful practices. In this connection it is said about the experiments of the Moscow Technological Institute in the use of modern information and educational technologies - the establishment and operation of a virtual "Club of political scientists" on the basis of the distance education system at MTI. The question about the prospects of these initiatives is set, that have already demonstrated their worth as educational, and as a pedagogic tool.
\end{abstract}

\section{Introduction}

The problem of extremist moods spread, unfortunately, has already become a part of the group of the most acute social problems in Russia. In the last two decades it has consistently been discussed at the highest state level. So, in "The Russian Federation National security Concept" and coming after "The Russian Federation National security Strategy" extremist activity of nationalist, religious, ethnic and other organizations was enumerated by the legislators of the main threats to national security. The fight against terrorism, extremism and xenophobia are definitely questioned by the President of the Russian Federation in his annual message to the Federal Assembly in recent years.

Such attention to the problem is quite justified. According to the official Russian statistics data, the number of crimes of extremist and terrorist orientation in recent years has rashly increased. According to the information about the state of crime in the country, published on the website of the Ministry of internal Affairs of the Russian Federation, only in January 2015 "88 crimes of a terrorist nature $(+63.0 \%)$ and 93 crimes of an extremist orientation (+24.0\%) were registered". In general, the 2015 year was highlighted with the following alarming figures: "In January - December 2015,1531 crimes of a terrorist nature $(+35.8 \%)$ and 1308 of extremist crimes $(+27.7 \%)$ were registered".

The fact that a significant part of these crimes was committed by teenagers and young people, including students of schools, colleges, universities, is a matter of extreme concern. According to expert estimates, about $80 \%$ of participants in the organizations of an extremist nature are persons whose age does not exceed 30 years [1]. This indicates the increasing radicalization of Russian youth and the growth of youth extremism, becoming, thus, one of the global problems of modern Russia, losing the future with the youth. In addition, among the most important trends of radicalization of Russian youth are the use of its formal and informal organizations as an instrument of ethno-political separatism and nationalism, the involvement of the youth in regional extremist groups, socio-political extremism of left-wing and right-wing radical informal youth organizations [2].

Russian history knows many examples of the radical minded youth participation, including - the students, in the political life of the country, participation which was marked by a number of bloody terrorist attacks. Intending at a time to solve the major political and socioeconomic problems of the country by force, these young radicals (populists, SRs, anarchists, etc.) spared neither theirselves nor their ideological opponents in a deadly struggle, the results of which, however, proved to be very far from expected.

Both then and now, the major sources of youth extremism may include the change of value bases of social development; deep political and socio-economic problems of the country; the inertia and corruption of power as a factor that generates and justifies any action to counter it; youthful maximalism with a lack of life experience, and sometimes culture [3].

Corresponding author: y_gorbuniva@mti.edu.ru 
It is obvious that in the organization of the fight against the spread of youth extremist mindsets, and even more, against the struggle with various manifestations resulting from such mindsets practice violent acts, the role of the state is great (creation and constant updating of the necessary legal framework, relevant national programs financing, the use of repressive measures, etc.) It is also clear, however, that it is impossible to break the situation with extremist manifestations in the country only with the forces and powers of state bodies. The effectiveness of building the opposition to these manifestations is conditioned not only by the strengthening of Russian statehood, but also the development of Russian civil society, establishment of constructive cooperation between the state and its institutions. In particular, with joint public and state efforts a large-scale explanatory and educational work can and should be organized, in which not only government agencies, but also the family, and the entire vertical of educational institutions of Russia - from school to university should participate [4].

\section{Analysis and discussion}

There are quite lot examples of such participation, especially as modern information and educational environment and new educational technologies provide new, previously unavailable opportunities. Under these conditions, the task of sharing a positive experience becomes urgent in the matter of:

- the development and implementation of prevention programs against the spread of extremist ideas among the youth,

- involving young people in a variety of social activities positive forms - hobby groups, clubs, community organizations, sport clubs, etc.

- formation of extremism ideology rejection through the mass media among the youth.

Such a positive experience to share, has Moscow Technological Institute (MTI), where over the last few years various educational programs in the educational process were tested, including programs aimed at counteraction terrorism and extremism ideologies expansion among students.

First of all, in April 2015, the Club of Political Scientists at the department of social and humanities at MTI was established and began its activities, initially regarded as a discussion platform for MTI students of MTI students enrolled in various bachelor and master programs. The first meeting of the club revealed, however, that not only students receiving higher education at MTI have the interest in the work of the Club, but also college students receiving secondary vocational education at MTI in different specialties in both humanitarian and technical areas. It has also been found out that students living in Moscow, where the parent institution is situated, are equally interested in the work of the Club with the students from various Russian regions and CIS countries studying at MTI with the use of distant learning technologies.

R.T. Verdiyev, a candidate of the political sciences, the expert of the Russian Federation State Duma National policy committee was invited as the leading of the club. He is an experienced practicing teacher, the author of books and articles of political and ethnological themes. R.T Verdiyev's teaching work awarded the prize of the Russian Federation Ministry of Education and Science "For the contribution to Russian Federation youth policy" (2001) and the prize of the Government of the North Ossetia-Alania Republic "For the contribution to the improvement of international relations in the Russian Federation" (2004) However, the decisive moment that allowed to choose the leading of the club, were not so much spoken above "regalia" of the candidate, but his ability to find a "common language" with students, willingness to communicate with them as equals, and not from the standpoint of "the teacher is always right" , friendliness and openness to different opinions, including those that do not coincide with his personal opinion.

The Club's work format was defined at the first club meetings - the most comfortable and productive form of interaction for their participants were weekly webinars in which club members had an opportunity not only so much to listen to traditional lectures and expert opinions of "senior comrades" on certain issues, as, getting food for thought, to share their own observations, opinions and estimates actively, to argue, to think.

The Club of Political Scientists electronic page was created in the system of distant learning at MTI, which was intended to announce the subject matter of upcoming meetings, but which almost immediately began to be used by students for a preliminary exchange of opinions on the topic of the next webinar, and for subsequent discussions on the results of the previous webinar. Very often there are links on the club page to certain, according to members of the Club, interesting materials and resources - political cultural, philosophical nature.

The announcement of the creation of the Club of Political Scientists provoked a lively response from the students, refuting the established view that the intellectual activities in modern Russia are an occupation for boring abstruse "nerds." The first virtual meetings in the club showed that it would become a permanent attribute of extracurricular activities from the experimental enterprise, carried out at the Moscow Technological Institute. Currently, (March 2016) the club has been active for almost a year, including summer sessions that were held at the request of students.

All participants of the club work were given the opportunity to propose interesting topics for discussion and the authors of the most valuable suggestions are appointed co-host of the webinar. In particular, in accordance with such proposals the discussions were held on the following themes: "The activities of international organizations" (an offer of a student M.M. Makhmudov, management specialty), "Political reasons for the beginning of the Great Patriotic War" (an offer of a student O.V. Baldina, Management specialty), "Revolution and color revolutions" (an offer of a student O.V. Lebedeva, Computer science and engineering specialty), "Current relations between Russia and the 
countries of the South America" (an offer of a student G.V. Domnikov, Technosphere security specialty), "What and how to do, to make the life of the Russians better?" (an offer of a student A.R. Arakelyan, Management specialty).

Many topics were and are discussed in the Club's webinars right "hot on the heels" of events unfolding before our eyes. Among the themes are: "St. Petersburg International Economic Forum 2015", "BRICS / SCO Summit of 2015", "Eastern Economic Forum 2015", "The problem of illegal migration in Europe", "Eurasian Women's Forum in St. Petersburg", "The Speech of Vladimir Putin, the President of Russia at the UN General Assembly in New York", "The final session of the discussion club «Valdai»", "APEC 2015", "Russia Turkey: modern technologies of international conflict settlement", "Davos 2016", "Krasnoyarsk economic forum 2016" etc.

It should be noted that the original idea of the founders of the Club of political scientists was aimed to achieve primarily educational goals - presentation of political science content with the use of new educational technologies, the popularization of political knowledge and awakening students' interest in modern political life of Russia and the world community, the production of their own views on controversial political issues, etc. But the first experience in a new format showed that the opened Club can and should be used not only as educational but also as an pedagogical tool, since it can be used to promote the intellectual development of students and improve their culture, primarily speech and behavioral.

The fact is that an open discussion of issues related to foreign and domestic policy of Russia, its position in the world, puts among the students the problem of not only rational, but also a moral choice. For example, the Club webinars, dedicated to the issues of inter-ethnic relations, religious tolerance, patriotism, terrorism, treatment of migrants, valid manifestations of political opposition, journalistic ethics, etc., could not proceed in a purely rational way and provide food only for the mind. The exchange of views on these issues inevitably touched the sphere of spirituality, forcing to think about "what is good and what is bad", and of the border, which is drawn between the culture of lawful and unlawful for an intelligent person.

In addition, the subject of the club webinar covers a number of issues, about which it is difficult to speak without excessive expression (including negative), as it befits the exchange of views among intelligent people. The problem is not that the students simply do not have enough vocabulary (although it happens sometimes), but in the fact that many of them are not ready to listen to other points of view properly and to defend their thoughts in the debate by calm rational argument. But they are ready to demonstrate firm confidence in the truth of their opinions, in connection with this allowing their selves arrogant neglect towards their ideological opponents - mocking and sharp expressions, including slang and some words bordering with abusive and even aggression. And indeed, - the denial, in principle, any compromises, negotiations, agreements - is one of the signs of the extremist mindset. Therefore, accompanying activities of the club work requires from the involved employees of the MTI to conduct the collective and individual preventive, motivational, counterpropaganda and informative talks.

Along with this, participation in political discussions develops many useful skills that will be useful to the Club members in professional and social life - the ability to work in a team, to find and analyze information, find quick or a compromise solution in a difficult situation, to accept a defeat in a dispute with dignity, etc.

\section{Conclusions}

Successful Start of the Club of Political Scientists pushed the organizers to the idea, supported by MTI headquarters to hold on its base the cycles of extracurricular webinars dedicated to particular socially significant issues. As a result, in December 2015 the first of these cycles was launched, during which the participants discussed a number of aspects of the terrorist threat hanging over the world today and every one of us. The second similar cycle, which starts in April 2016, will be devoted to topical issues of the fight against drug addiction.

You can talk about different perspectives of the Club of Political Scientists at MTI development - this is the possibility of organizing series of meetings with representatives of business, government, various public and party organizations in Russia, and the possibility of organizing student videoconferences of current political issues, and the possibility of organizing club meetings not only virtual, but also in real space. Anyway, the club will continue its activities encouraging young people to spend their time not with frivolous entertainment or discussion of the "mega-news" of show business, not in idleness, or the sects and extremist organizations, but in disputes about the fate of the world community and the place of Russia in it, in erudition competitions, in exposures of the political intrigues, in learning the bases of social and political activities and state-building.

\section{References}

1. Guidelines for the prevention and extremism counteraction in the youth environment (developed by Ministry of Sports of Russia jointly with the Russian Interior Ministry) 40 (2011)

2. E.V. Tregubova, The factors of youth extremism determination in modern Russia. In Proc. conference Educational environment today and tomorrow, p. $499-503$ (2015)

3. E.O. Kubykin, Social and socio-cultural foundations of youth extremism in modern Russia, Law and society. 1, 273-276 (2011)

4. B.A. Smirnov, Youth policy: experience of system description. Sociological researches, 2, 72-79 (2014) 